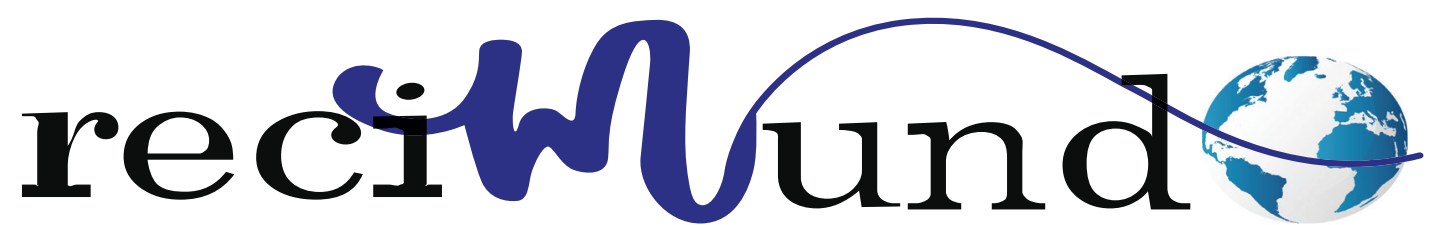

Revista Científica Mundo de la Investigación y el Conocimiento

DOI: 10.26820/recimundo/4.(1).esp.marzo.2020.100-113

URL: http://recimundo.com/index.php/es/article/view/783

EDITORIAL: Saberes del Conocimiento

REVISTA: RECIMUNDO

ISSN: 2588-073X

TIPO DE INVESTIGACIÓN: Artículo de Revisión

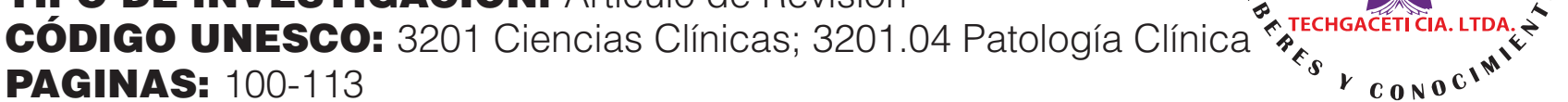

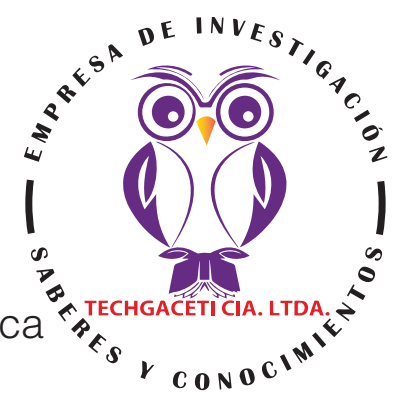

\title{
Cáncer de mama ligado al gen BRCA1
}

Breast cancer linked to the BRCA1 gene Câncer de mama ligado ao gene BRCA1

Katherine Elizabeth Almeida Barba'; Andrea Michelle Castillo González²; Raysa Astrid Fuertes Arévalo³;

David Fernando Rodríguez Becerra ${ }^{4}$

\section{RECIBIDO: 20/11/2019 ACEPTADO: 29/01/2020 PUBLICADO: 05/03/2020}

1. Médico; Investigadora Independiente; Quito, Ecuador; kathyelialb@gmail.com; (D) https://orcid.org/0000-00024404-3059

2. Médico; Investigadora Independiente; Quito, Ecuador; adreikicastillo@gmail.com; (D) https://orcid.org/00000001-5569-5952

3. Médico; Investigadora Independiente; Quito, Ecuador; raysafuertesa@gmail.com; (D) https://orcid.org/00000003-0064-7528

4. Médico; Investigador Independiente; Quito, Ecuador; dav_fercho@hotmail.com; (D) https://orcid.org/00000002-5195-4248

CORRESPONDENCIA

Katherine Elizabeth Almeida Barba

kathyelialb@gmail.com

Quito, Ecuador 


\section{RESUMEN}

El cáncer de mama (CM) es uno de los cánceres humanos más comunes en el mundo. Esta neoplasia se ha incrementado de una manera sostenida desde 1990 y se prevé que este incremento continúe. Los factores de riesgo para esta enfermedad son: la edad, algunos factores reproductivos, las radiaciones ionizantes, el uso de anticonceptivos, la obesidad y dietas altas en grasa, entre otros. El mayor factor de riesgo para el CM es una historia familiar positiva. En los casos de agregación familiar donde no se puede demostrar un patrón mendeliano, el desarrollo del CM se debe probablemente a mutaciones en genes de baja penetrancia y/o a factores ambientales. Otras familias presentan un patrón de herencia autosómico dominante en las cuales son frecuentes mutaciones en los genes BRCA1 y BRCA2. Mutaciones en el gen BRCA1 predisponen predominantemente al CM y al cáncer de ovario, mientras que mutaciones en el gen BRCA2 predisponen al $\mathrm{CM}$ tanto en mujeres como en varones. Ambos genes son de gran tamaño, actúan como supresores de tumores, funcionan de una manera dependiente del ciclo celular y se piensa que los dos participan, tanto en la activación de la transcripción de diversos genes, como en la reparación del DNA. El patrón de mutaciones en los genes BRCA1 y BRCA2 es ampliamente-te conocido en los países desarrollados, aunque en Latinoamérica apenas inician algunos estudios en este sentido. El manejo de pacientes con mutaciones en estos genes debe realizarse por un equipo multidisciplinario, y la asignación de riesgo y el asesora-miento genético deben ser hechos de una manera cuidadosa.

Palabras clave: Cáncer, Mama, Epidemiología, Riesgo, Genética, BRCA1, BRCA2.

\section{ABSTRACT}

Breast cancer is among the most common world cancers. This neoplasm has been progressively increasing since 1990 and is expected to continue. The risk factors for this disease are age, some reproductive factors, ionizing radiation, contraceptives, obesity and high fat diets, among other factors. The main risk factor for BC is a positive family history. Several families, in which clustering but no mendelian inheritance exists, the BC is due probably to mutations in low penetrance genes and/or environmental factors. In families with autosomal dominant trait, the BRCA1 and BRCA2 genes are frequently mutated. These genes are the two main BC susceptibility genes. BRCA1 predispose to BC and ovarian cancer, while BRCA2 mutations predispose to BC in men and women. Both are long genes, tumor suppressors, functioning in a cell cycle dependent manner, and it is believed that both switch on the transcription of several genes, and participate in DNA repair. The mutations profile of these genes is known in developed countries, while in Latin America their search has just began. A multidisciplinary group must be responsible of the clinical management of patients with mutations in BRCA1 and BRCA2, and the risk assignment and Genetic counseling must be done carefully.

Keywords: Cancer, Breast, Epidemiology, Risk, Genetics, BRCA1, BRCA2.

\section{RESUMO}

O câncer de mama está entre os cânceres mais comuns no mundo. Essa neoplasia tem aumentado progressivamente desde 1990 e espera-se que continue. Os fatores de risco para essa doença são: idade, alguns fatores reprodutivos, radiação ionizante, contraceptivos, obesidade e dietas ricas em gordura, entre outros fatores. O principal fator de risco para BC é uma história familiar positiva. Várias famílias, nas quais existem agrupamentos, mas nenhuma herança mendeliana, o BC deve-se provavelmente a mutações em genes de baixa penetrância e / ou fatores ambientais. Em famílias com característica autossômica dominante, os genes BRCA1 e BRCA2 são frequentemente mutados. Esses genes são os dois principais genes de suscetibilidade ao BC. O BRCA1 predispõe ao BC e câncer de ovário, enquanto as mutações do BRCA2 predispõem ao BC em homens e mulheres. Ambos são genes longos, supressores de tumor, funcionando de maneira dependente do ciclo celular, e acredita-se que ambos ativem a transcrição de vários genes e participem do reparo do DNA. O perfil de mutações desses genes é conhecido nos países desenvolvidos, enquanto na América Latina sua pesquisa está apenas começando. Um grupo multidisciplinar deve ser responsável pelo manejo clínico de pacientes com mutações no BRCA1 e BRCA2, e a atribuição de riscos e o aconselhamento genético devem ser realizados com cuidado.

Palavras-chave: Câncer, Mama, Epidemiologia, Risco, Genética, BRCA1, BRCA2. 


\section{Introducción}

El conocimiento de diversos factores implicados en el desarrollo del CM se ha incrementado de una manera importante en la última década. Debido a la importancia que ha cobrado esta neoplasia en nuestros países como consecuencia de la elevación de su frecuencia y su mortalidad, es muy deseable que el personal de salud conozca los aspectos relevantes de estos avances, por lo cual, la intención de esta revisión es aportar conocimiento sobre los diversos factores implicados en el desarrollo del CM, con especial énfasis en el aspecto genéti$\mathrm{co}$.

El cáncer de mama (CM) se encuentra entre los cánceres humanos más comunes, con cerca de trescientas mil mujeres muriendo por esta enfermedad cada año en el mundo(Pisani, Parkin, \& Bray, 2009) En los Estados Unidos de Norteamérica (EUA) el CM se incrementó de una manera sostenida desde 1930 con un aumento promedio de $1.2 \%$ por año según fue descrito por (Holford, Roush, \& McKay, 2011) Más de 180,000 mujeres en aquella nación son diagnosticadas cada año con CM, representando el $32 \%$ de todos los cánceres incidentes en EUA; de ellas, 50,000 mueren como consecuencia de la enfermedad. Sin embargo, estudios recientes revelan una disminución en la mortalidad en los últimos años(Chu \& Tarone, 2016). Aunque se piensa que el aumento en la frecuencia es debido al envejecimiento de la población y al advenimiento de mejores métodos de diagnóstico (especialmente la mamografía), estos mismos factores y la aparición de mejores alternativas de tratamiento, se han postulado como responsables de la disminución en la mortalidad. También se reconoce el papel que pueden jugar cam-bios en el medio ambiente y en el estilo de vida, en el incremento de la frecuencia del CM.

(Bondy \& Spitz, 2012) encontraron una menor frecuencia de CM en la población his- pana al compararla con las poblaciones caucásica y afroamericana. En ese estudio $10 \%$ de las mujeres hispanas, $24 \%$ de las mujeres caucásicas y $18 \%$ de las mujeres afroamericanas eran nulíparas. El promedio de número de hijos por mujer fue de 3.6 para las hispanas, 2.0 para las caucásicas y 2.8 para las afroamericanas; $42.9 \%$ de las mujeres hispanas tuvieron hijos entre los 2024 años, mientras que esto mismo fue cierto solo para el $28 \%$ de las mujeres caucásicas y afroamericanas. Por lo tanto, ellos atribuyeron a estos factores la baja frecuencia de CM entre las hispanas. Sin embargo, a despecho de estos hallazgos, en Méxi-co está ocurriendo un fenómeno epidemiológico semejante al vivido hace algunos años en los países desarrollados, con un incremento progresivo del CM. Los Registro Histopatológico de Neoplasias están realizando grandes esfuerzos para obtener una estadística confiable de la incidencia de cáncer, pero los informes aún son incompletos. Parte de la explicación de este incremento se encuentra en cambios en el estilo de vida de la población y en cambios en los patrones reproductivos. 8

Debido a la magnitud de este problema de salud pública, al deseo de reducir el impacto de esta enfermedad en las mujeres y a la accesibilidad del tejido mamario canceroso para investigación, un creciente número de investigadores se ha enfocado sobre esta enfermedad en años recientes. Estos esfuerzos han rendido resultados, permitiéndonos conocer ahora las regiones del genoma humano que albergan a los dos principales genes de susceptibilidad para esta enfermedad: BRCA1 y BRCA2; así como varios genes más que se encuentran alterados en células somáticas en los casos de CM esporádico. Los avances en esta área han provisto las herramientas necesarias para trasladar los descubrimientos científicos a la práctica clínica, como un medio para proveer la detección, tratamiento y últimamente la prevención de esta enfermedad. 


\section{Metodología}

Para el desarrollo de este proceso investigativo, se plantea como metodología la encaminada hacia una orientación científica particular que se encuentra determinada por la necesidad de indagar en forma precisa y coherente una situación, en tal sentido (Davila, 2015) define la metodología "como aquellos pasos previos que son seleccionados por el investigador para lograr resultados favorables que le ayuden a plantear nuevas ideas".(p.66)

Lo citado por el autor, lleva a entender que el desarrollo de la acción investigativa busca simplemente coordinar acciones enmarcadas en una revisión bibliográfica con el fin de complementar ideas previas relacionadas al cáncer de mama vinculado al gen BRCA1 a través de una revisión de literatura, para así finalmente elaborar un cuerpo de consideraciones generales que ayuden a ampliar el interés propuesto.

\section{Tipo de Investigación}

Dentro de toda práctica investigativa, se precisan acciones de carácter metodológico mediante las cuales, se logra conocer y proyectar los eventos posibles que la determinan, así como las características que hacen del acto científico un proceso interactivo ajustado a una realidad posible de ser interpretada. En este sentido, se puede decir, que la presente investigación corresponde al tipo documental, definido por Castro (2016), "se ocupa del estudio de problemas planteados a nivel teórico, la información requerida para abordarlos se encuentra básicamente en materiales impresos, audiovisuales y /o electrónicos". (p.41).

En consideración a esta definición, la orientación metodológica permitió la oportunidad de cumplir con una serie de actividades inherentes a la revisión y lectura de diversos documentos donde se encontraron ideas explicitas relacionadas con los tópicos en- cargados de identificar a cada característica insertada en el estudio. Por lo tanto, se realizaron continuas interpretaciones con el claro propósito de revisar aquellas apreciaciones o investigaciones propuestas por diferentes investigadores relacionadas con el tema de interés, para luego dar la respectiva argumentación a los planteamientos, en función a las necesidades encontradas en la indagación.

\section{Fuentes Documentales}

El análisis correspondiente a las características que predomina en el tema seleccionado, llevan a incluir diferentes fuentes documentales encargadas de darle el respectivo apoyo y en ese sentido cumplir con la valoración de los hechos a fin de generar nuevos criterios que sirven de referencia a otros procesos investigativos. Para (CASTRO, 2016) las fuentes documentales incorporadas en la investigación documental o bibliográfica, "representa la suma de materiales sistemáticos que son revisados en forma rigurosa y profunda para llegar a un análisis del fenómeno".(p.41). Por lo tanto, se procedió a cumplir con la realización de una lectura previa determinada para encontrar aquellos aspectos estrechamente vinculados con el tema, con el fin de explicar mediante un desarrollo las respectivas apreciaciones generales de importancia.

\section{Técnicas para la Recolección de la Infor- mación}

La conducción de la investigación para ser realizada en función a las particularidades que determinan a los estudios documentales, tiene como fin el desarrollo de un conjunto de acciones encargadas de llevar a la selección de técnicas estrechamente vinculadas con las características del estudio. En tal sentido, (Bolívar, 2015), refiere, que es "una técnica particular para aportar ayuda a los procedimientos de selección de las ideas primarias y secundarias". (p. 71). 
Por ello, se procedió a la utilización del subrayado, resúmenes, fichaje, como parte básica para la revisión y selección de los documentos que presentan el contenido teórico. Es decir, que mediante la aplicación de estas técnicas se pudo llegar a recoger informaciones en cuanto a la revisión bibliográfica de los diversos elementos encargados de orientar el proceso de investigación. Tal como lo expresa, (Bolívar, 2015) "las técnicas documentales proporcionan las herramientas esenciales y determinantes para responder a los objetivos formulados y llegar a resultados efectivos" (p. 58). Es decir, para responder con eficiencia a las necesidades investigativas, se introdujeron como técnica de recolección el método inductivo, que hizo posible llevar a cabo una valoración de los hechos de forma particular para llegar a la explicación desde una visión general.

Asimismo, se emplearon las técnicas de análisis de información para la realización de la investigación que fue ejecutada bajo la dinámica de aplicar diversos elementos encargados de determinar el camino a recorrer por el estudio, según, (Bolívar, 2015) las técnicas de procesamiento de datos en los estudios documentales "son las encargadas de ofrecer al investigador la visión o pasos que debe cumplir durante su ejercicio, cada una de ellas debe estar en correspondencia con el nivel a emplear" (p. 123). Esto indica, que para llevar a cabo el procesamiento de los datos obtenidos una vez aplicado las técnicas seleccionadas, tales como: fichas de resumen, textual, registros descriptivos entre otros, los mismos se deben ajustar al nivel que ha sido seleccionado.

\section{Resultados}

La etiología del CM es multifactorial, ya que intervienen en ella factores genéticos, endocrinos, socioculturales, fisiopatológicos, etc. Los factores de riesgo para CM han sido investigados desde hace tiempo con el propósito de encontrar modificaciones a diferentes aspectos del estilo de vida que permitan disminuir el riesgo de padecer CM. Entre los más importantes factores de riesgo se encuentran los siguientes:

Historia familiar positiva. El mayor factor de riesgo para el desarrollo de CM es una historia familiar positiva. Los genes BRCA1 y BRCA2 son los principales genes de susceptibilidad para la enfermedad, mientras que recientemente se ha descubierto y se encuentra en vías de exploración el gen BRCA3(Seitz, Rohde, \& Bender, 2017). Sin embargo, mutaciones en estos genes no explican todos los CM familiares, por lo cual es posible que existan otros genes debaja penetrancia para CM aún pendientes de ser identificados. El riesgo relativo $(R R)$ para CM con respecto a una historia familiar positiva, es de 2 para una mujer cuya madre o hermana fue diag-nosticada con CM, 10 para los familiares de primer grado cuando el CM se presenta en etapa premenopáusica y es bilateral y hasta 150 para una mujer de 40 años portadora de una mutación en el gen BRCA1.

Edad. El riesgo relacionado con la edad va desde 1 en 20,000 para una mujer menor de 25 años, hasta 1 en 9 para mujeres de 85 años y mayores. El riesgo de padecer CM en mujeres jóvenes (< 35 años) es menor que en mujeres de más edad. Sin embargo, cuando el CM se presenta en ellas, la severidad y agresividad del CM es más alta. Se piensa que esos tumores son biológicamente diferentes y la idea está sustentada en el hecho de que los tumores en estas pacientes tienen más altos niveles de proliferación y son menos diferenciados que los tumores de mujeres mayores de 35 años. En general las mujeres jóvenes con CM tienen un tiempo corto libre de la enfermedad y poca sobrevida(Henderson \& Patek, 2007)

Factores reproductivos.(Trichopoulos, D, \& Macmahom, 2002) encontraron que una menarquia antes de los 12 años (RR: 1.2), 
la multiparidad (RR: 2), y una menopausia después de los 50 años (RR: 2 a 5) son factores de riesgo importantes. (Tokunaga \& Land, 2009)por su parte, han postulado que todos esos factores provocan un incremento en el número de ciclos menstruales comparado con las mujeres multíparas, con el consecuente incremento en la exposición del tejido mamario a la acción estrogénica.

Radiaciones ionizantes. La radiación es también un factor de riesgo para CM, lo cual es atestiguado al menos por dos ejemplos: se observó un incremento significativo entre las mujeres su-pervivientes a la bomba atómica (RR: 13) y en las mujeres que han recibido radiación por enfermedad de Hodgkin (RR: 75.3). El tejido mamario es moderadamente sensible a la radiación, de-bido a variaciones en la proliferación celular como consecuencia de las variaciones hormonales con los ciclos menstruales; siendo dicha proliferación baja durante la fase folicular y aumentando hasta cuatro veces a mitad de la fase lútea(Goss \& Sierra, 2011)

Lactancia. Algunos investigadores han postu-lado que el amamantamiento ejerce un efecto protector contra el CM porque durante la segunda fase del embarazo y de la lactancia, el estriol y la progesterona (dos hormonas que no incrementan el riesgo de CM) dirigen la maduración de los lobulillos de la glándula; mientras que el estradiol y la estrona, cuyo efecto es la proliferación del epitelio ductal, lo hacen en la mujer menstruante. Existen, además, otras hipótesis que explican el efecto protector de la lactancia: Una de ellas es que la acción directa de la hipófisis sobre la acti-vidad ovárica cambia el estado hormonal postparto de la mujer, lo cual reduce los niveles de estrógenos a través de la supresión de la ovulación. Como resultado de esto, la exposición acumulada a los estrógenos se reduce. Otra hipótesis que explicaría el efecto protector del amamantamiento es que la lactancia favorece la expulsión de carcinógenos a través de la leche. Estudios experimentales que han evaluado la inducción de tumores mamarios en ratones han demostrado el desarrollo de un mayor número de tumores en mamas a las que se les quitó el pezón que en mamas normales, sugiriendo que la obstrucción del pezón resulta en una prolongada exposición a carcinógenos.

Uso de anticonceptivos. La mayoría de los investigadores coinciden en que no existe relación directa entre el uso de anticonceptivos y CM.Sin embargo, la ingesta prolongada con-duce a cambios de hiperplasia en el epitelio vaginal, cervical y mamario en pacientes jóvenes sin antecedentes de paridad y con historia de mastopatía fibroquística.Por otro lado, algunos estudios sugieren que el uso de anticonceptivos orales puede incrementar el riesgo de CM entre las portadoras de mutaciones en el gen BRCA1(Ursin \& Henderson, 2017).

Dietas altas en grasa y obesidad. Diferentes evidencias sustentan la relación entre obesidad y CM: estudios epidemiológicos en grupos de inmigrantes asiáticos a Occidente y el consecuente cambio en sus costumbres provoca un aumento en la tasa de incidencia y mortalidad por CM en las generaciones subsecuentes. Además, se ha demostrado el papel de las grasas polinsaturadas en la génesis del CM. Experimentalmente se ha demostrado que cuando animales de laboratorio son sujetos a una dieta rica en grasas polinsaturadas, especialmente dietas grasas con alto contenido de ácido linoleico (al que se conoce como pre-cursor de las prostaglandinas que actúan como mediadores de la génesis tumoral), estos desarrollan tumores mamarios. Por otro lado, la estimulación estrogénica en ausencia de secreción de progesterona puede promover el desarrollo de CM en mujeres premenopáusicas obesas con ovarios poliquísticos e inadecuada función del cuerpo lúteo. En la menopausia la suspensión de la función ovárica favorece la movilización de tejido adiposo de la mama y de los tejidos periféricos, estimulando la 
producción de androstenediona, estrona y estriol.

Factores adicionales que se han propuesto como de riesgo para CM en algunos, pero no en todos los estudios son: Aborto, patología mamaria previa, ingesta de alcohol, falta de ejercicio, y terapia estrogénica de reemplazo.

\section{Genética}

El CM es una enfermedad compleja y heterogénea causada por la interacción de factores genéticos y no genéticos. Sin embargo, una historia familiar de CM ha sido reconocida desde hace mucho tiempo como un factor de riesgo. Aunque los términos CM familiar y CM hereditario son frecuentemente utilizados en el mismo sentido, es necesario hacer una distin-ción entre estos dos conceptos. El CM de tipo heredi-tario es aquel en el cual la historia familiar sugiere la presencia de un gen dominante de alta penetración para CM. El CM de tipo familiar implica que dos o más familiares de primer grado han tenido CM y en los cuales se piensa que algunos factores ambientales a los que la familia está expuesta subyacen a la enfermedad(Hill \& Doyle, 2007). Tales factores incluyen la exposición a carcinógenos en un área geográfica determinada que pueden afectar a varios miembros de la familia que vivan en la misma área, factores étnicos y culturales que afectan el estilo y costumbres de vida, como por ejemplo la edad a la que se tiene el primer parto, el uso de anticonceptivos y el nivel socioeconómico que influye en el tipo de dieta que los individuos tienen.4 Los casos familiares representan cerca del $23 \%$ de todos los casos de CM.

Por otro lado, el CM de tipo hereditario presenta varias características distintivas: la edad de apari-ción de la enfermedad es considerablemente menor que en los casos esporádicos, la prevalencia de cáncer bilateral es más alta, y en algunas familias ocu- rre la presencia de otros tumores en los individuos afectados. Entre los más comunes de tales tumores están: el cáncer de ovario, el de colon, el de próstata, el de endometrio y los sarcomas. Se piensa que el CM de tipo hereditario representa del 3 al 10\% de todos los CM y que factores hereditarios son responsables del 25 al 35\% de todos los casos diagnosticados antes de los 30 años. El riesgo relativo (RR) de desarrollar $\mathrm{CM}$ es de 3.1 en un familiar de primer grado de una mujer con CM de inicio temprano, de 5.4 en las formas bilaterales y de 8.8 en las mujeres con $\mathrm{CM}$ bilateral más inicio temprano. Existe controversia en cuanto al riesgo para los familiares de segundo y tercer grado, ya que mientras algunos estudios les asignan el mismo riesgo que para la población general,otros autores refieren un RR de 1.8 para los familiares de segundo grado y 1.4 para los de tercer grado.

\section{El gen BRCA1}

En 1990 se identificó por análisis de ligamiento en el cromosoma 17 en 17q21 la región dentro de la cual se encuentra el primer gen de susceptibilidad al CM, llamado ahora BRCA1(Narod \& Feuteun, 2011) El gen fue clonado (insertado en un plásmido e introducido en una bacteria para producir múltiples copias) y secuenciado (se conoció el orden en que se encuentran las bases $A, T, G$ y $C$ en ese gen). En un estudio realizado en 214 familias se detectó que sólo el 45\% de ellas presentaban ligamiento a marcadores de este gen. Sin embargo, el porcentaje de familias con mutaciones (con cambios en la secuencia nucleotídica normal de los genes) en BRCA1 se elevó al $70 \%$ cuando la edad de diagnóstico del CM fue de menos de 45 años. La frecuencia estimada de mutaciones en el gen BRCA1 en la población general según ese estudio es de aproximadamente 1 en 2,000(Easton, Bishop, \& Ford, 2012).

En la mayoría de las familias con menos de cuatro casos de CM o cáncer de ovario, 
la causa frecuente-mente no se encuentra relacionada con mutaciones en el gen BRCA1. Sin embargo, cuando existen de dos o más casos de inicio temprano y/o dos o más casos de cáncer de ovario, la probabilidad de encontrar muta-ciones en este gen es del $92 \%$.

Estudios iniciales estimaron que las portadoras de mutaciones en el gen BRCA1 tienen un riesgo del $87 \%$ de desarrollar CM y $40-60 \%$ de desarrollar cáncer de ovario en algún momento de su vida, sin embargo, en estudios posteriores realizados por Struewing y cols. en mujeres y hombres judíos, el riesgo de desarrollar CM fue del $56 \%$, cáncer de ovario 16\% y cáncer de próstata 16\%. La explicación de esta diferencia estriba en el sesgo que probablemente tuvieron los primeros estudios, debido a que en ellos fueron seleccio-nadas las familias con mayor número de casos tanto de $\mathrm{CM}$ como de ovario y con mayor cantidad de mujeres jóvenes. El riesgo de desarrollar formas bilaterales de CM es también mucho más alto en portadoras (aquellas que tienen un alelo mutado y uno normal). Las hijas de portadoras tienen un riesgo del $50 \%$ de heredar el gen mutante y por lo tanto de desarrollar CM o cáncer de ovario.

En los casos familiares, la mayoría de las mutacio-nes descritas son germinales (ocurren previo a la fecundación y por lo tanto están en todas las células del individuo), mientras que es raro encontrar mutacio-nes en líneas somáticas (es decir, que ocurren en una célula no germinal) tanto en los casos familiares como en los esporádicos. Prácticamente todas las pacientes se encuentran en estado heterocigoto para la mutación (es decir, que tienen un alelo normal y uno mutado). Una sola persona ha sido descrita como homocigota (con los dos alelos mutados) para este gen, habiendo heredado un alelo mutado de cada uno de los padres. Esta persona homocigota se desarrolló normalmente, pero presentó CM a la edad de 32 años(Boyd \& Harris, 2015).
Se han utilizado una gran variedad de técnicas para detectar mutaciones en el gen BRCA1, inclu-yendo el análisis de polimorfismos conformacionales de cadena sencilla (SSCP) y recientemente la técnica de DHPLC, el ensayo de la proteína truncada (PTT), el análisis de heterodúplex (HDA) y la secuenciación directa. Estudios describiendo las primeras variantes en el gen BRCA1 mostraron que el $55 \%$ se encuentran localizadas en el exon, lo cual no es sorprendente, debido a que este exon contiene el $62 \%$ de la secuencia codificante. Del total de mutaciones $52 \%$ han sido detectadas una sola vez y el $87 \%$ de ellas dan como producto proteínas truncadas o ausencia de la proteína. Ciento noventa y seis de ellas provocan cambios en el marco de lectura con la aparición de codones prematuros de terminación y han sido detectadas variantes de "splicing" (lo que crea también cambios en el marco de lectura y codones prematuros de terminación de la traducción). Las variantes restantes han sido de cambio de sentido no truncantes dentro de la secuencia codificante del gen.

Se ha descrito que mutaciones en la mitad 5' del gen BRCA1 predisponen a cáncer de mama y ovario, mientras que mutaciones en la mitad 3' están predominantemente asociadas de manera específica a CM75. Mutaciones localizadas en las dos regiones terminales del gen, parecen estar asociadas a un fenotipo más severo, sugiriendo que esas dos regionespueden ser importantes en el control del desarrollo celular de la glándula mamaria.

Estudios por fraccionamiento celular e inmu-nofluorescencia han mostrado que la proteína BRCA1 tiene localización intranuclear en células normales, mientras que en células cancerosas se localiza tanto en el núcleo como en el citoplasma, sugiriendo que la localización celular inadecuada de esta proteína pudiera ser un mecanismo por el cual BRCA1 juegue un papel en la patogénesis de los tumores mamarios. 
El gen BRCA1 tiene similitud con la secuencia consenso de una granina. Las graninas son pro-teínas secretadas y modificadas para formar péptidos bioactivos que actúan en la superficie celular. Si la proteína BRCA1 fuera secretada este sería un hecho inusual para un gen supresor de tumores. Sin embargo, existen evidencias que muestran que los anticuerpos usados en los experimentos descritos, tienen reacción cruzada con el factor de crecimiento epidérmico, una molécula expresada en la superficie celular, por lo cual es posible que lo que se encontró como producto de secreción sea el factor de crecimiento epidérmico y no la proteína BRCA1. Adicionalmente, se sabe que el dominio semejante a las graninas no es una secuencia alta-mente conservada de manera evolutiva, lo cual evidencia que probablemente no es importante para la función del gen (Jensen \& Thompson, 2006).

Aún antes de que se aislara el gen BRCA1 se predijo que tenía una función supresora de tumores. Estas predicciones se basaron en el hecho de que las mujeres heterocigotas en línea germinal para este gen, presentaban pérdida de la heterocigocidad cuando se analizaban las células tumorales. Estu-dios experimentales donde se hace transferencia retroviral del gen BRCA1 tipo silvestre (el gen normal, no mutado) a líneas celulares tumorales de mama y ovario, demuestran que se inhibe el desarrollo del tumor. También ha sido demostrado que el desarrollo de tumores MCF-7 en el ratón desnudo es inhibido cuando existe BRCA1 tipo silvestre, aún en presencia del gen BRCA1 endógeno mutado, reforzando la idea de que el gen BRCA 1 funciona como un gen supresor de tumores(Holt \& Thompson, 2006).

El gen BRCA1 está compuesto de 24 exones (las secuencias que codifican para la proteína), de los cuales 22 son transcritos, originando un ARNm de $7.8 \mathrm{~kb}$ de longitud que se traduce en una proteína de 1,863 aminoácidos. El gen entero tiene 5,592 nucleótidos distribuidos en aproximadamente 100 kb del DNA genómico. Su estructura es inusual, con la mayoría de los exones en el rango esperado de $100-500 \mathrm{pb}$, pero con el exon 11 constituyendo aproxi-madamente el 60\% (alrededor de 3500 pb) de la región codificante.

El gen BRCA1 posee 126 pares de bases de simili-tud con una región génica que codifica para un do-minio del tipo "dedo de zinc", cercano al extremo $5^{\prime}$ del gen, sugiriendo que la proteína BRCA1 puede funcionar como un factor de transcripción. En la proteína, este dominio dedo de zinc presenta un conjunto de residuos de cisteína e histidina creando un sitio de unión para el ión zinc, el cual induce el plegamiento de la cadena aminoacídica para formar un bucle. Aproximadamente el $1 \%$ de todos los ge-nes humanos incluye la secuencia para este tipo de estructura.

\section{Manejo clínico y aspectos éticos}

No todas las mujeres con CM son candidatas a un estudio genético. En general la prueba debe ser considerada en primer término en mujeres afectadas con $\mathrm{CM}$ y que pertenecen a familias de alto riesgo, es decir, aquellas que han tenido al menos tres familiares de primer grado afectados de CM y/u ovario. Es-tos casos frecuentemente son de inicio temprano, de tipo bilateral y/o CM en varones. No es adecuado el estudio inicial en personas no afectadas con historia familiar positiva, debido a que un resultado negativo en ellas, no descarta que los miembros afectados sí tengan una mutación.

La decisión para proceder con la prueba de detección de mutaciones en BRCA1 y BRCA2 es compleja. Para establecer el riesgo en una paciente, es necesaria la obtención precisa y detallada de la historia familiar. (Shattuck-Eidens, McClure, Simard, Labrie, \& Narod, 2005)analizando un total de 1,086 mujeres con CM y/u ovario, publi- 
caron estimados de probabilidad de tener mutaciones en los genes BRCA1 y BRCA2, basados en la edad e historia personal y familiar.

La historia familiar debe ser lo más detallada posible en cuanto a casos de cáncer, tanto por rama pa-terna como por rama materna, así como detallando la posición de los familiares afectados dentro del árbol genealógico; los familiares no afectados deben también ser incluidos, dado que la distribución de afectados y no afectados en el árbol genealógico sugiere el modo de herencia. La información debe in-cluir un mínimo de tres generaciones cuando sea posible. Los datos de la historia familiar deberían ser confirmados por obtención de los reportes histopatológicos para asegurar la exactitud del diagnóstico. También podría ser útil obtener la historia familiar de más de un miembro de la familia para cotejar la información obtenida. Deben ser obtenidos también detalles tales como la edad de diagnóstico, edades de los individuos no afectados, tipo histológico, sitio del tumor primario y presencia de metástasis. Es importante también tomar nota de la presencia de algunas enfermedades hereditarias que predisponen a los in-dividuos a una gran variedad de neoplasias como el síndrome de Li-Frameni, la anemia de Fanconi y la ataxia telangiectasia. Una vez que se detecta una mutación en una mujer afectada, se puede realizar la búsqueda específica de esa mutación en el resto de los miembros de la familia para la detección de posi-bles portadores.

Sin embargo, la gran mayoría de mujeres con his-toria familiar positiva, caen en la categoría de riesgo moderado. Estas familias se caracterizan por una historia familiar de CM menos fuerte, la ausencia de casos de cáncer de ovario y diagnóstico de la enfermedad a edades avanzadas. Las bases moleculares para explicar el riesgo de cáncer de mama en estas familias son menos conocidas que para las familias de alto riesgo, pero frecuentemente no se deben a mutaciones en un gen autosómico dominante. La historia familiar en esas situaciones, típicamente revela la presencia de uno o dos familiares con cáncer de mama (frecuentemente en etapa posmenopáusica) y no existen antecedentes de otros tipos de tumores. Las causas de agregación familiar en este grupo pue-den deberse a: 1) El efecto combinado de múltiples componentes genéticos y agentes ambientales; 2) La presencia de un gen dominante de baja penetrancia;

La presencia de un gen autosómico dominante, pero que debido a una historia clínica incompleta no puede ser determinado por el análisis del árbol ge-nealógico y 4) la aparición de dos casos o más de CM por azar, debido a que cada mujer tiene un riesgo de por vida del 10\% de desarrollar la enfermedad(Hoskins, Stopfer, \& JE., 2005).

Existe un acuerdo general entre los investigado-res y consejeros genéticos de que las mujeres en familias de alto riesgo deben tener la oportunidad de decidir individualmente si se les realiza o no la prueba para detección de mutaciones en los genes BRCA. Sin embargo, actualmente existen algunas incertidumbres con respecto a la prueba: la distinción entre los verdaderos y los falsos positivos es difícil, debido a que cuando los resultados son negativos, las mutaciones podrían encontrarse en los intrones o en la región regulatoria del gen, o bien, podría haber susceptibilidad genética a otros genes distintos a BRCA1 y BRCA2.

Un resultado negativo es mas útil cuando ha sido detectada previamente una mutación en un familiar de primer grado. Sin embargo, una mujer en esta si-tuación, aún tiene el mismo riesgo de desarrollar cáncer de mama y de ovario que la población general. Por otro lado, el hallazgo de una variante genética puede no representar una verdadera mutación. No está demostrado que todos los alelos "anormales" confieran susceptibilidad al cáncer, incluso mu-

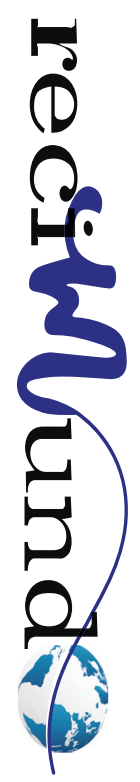


tacio-nes conocidas proporcionan riesgos distintos en dife-rentes familias; así, asignar un riesgo preciso para cada mutación es muy difícil. El gran tamaño de los genes y la gran cantidad de mutaciones que han sido descritas a lo largo de ellos hacen la prueba difícil de realizar y ponerla a disposición de los laboratorios en la práctica clínica diaria. También existe siempre algún riesgo de no interpretar los resultados adecua-damente y colocar a una familia en una categoría inadecuada de riesgo.

Aunque existe cierta controversia acerca de las medidas diagnósticas y terapéuticas a tomar y la par-ticipación en protocolos de investigación de las familias con alto riesgo de padecer CM (como aquellas que presentan mutaciones en los genes BRCA1 y BRCA2), se ha establecido un consenso entre los ex-pertos para el manejo de este tipo de pacientes.

En portadoras o posibles portadoras de mutacio-nes en los genes BRCA1 y BRCA2 se recomiendan las siguientes medidas: autoexamen mamario cada mes después de los 18 años; examen mamario por ex-pertos clínicos cada seis meses a un año iniciando entre los 25 y 35 años; realizarse una mamografía anual iniciando entre los 25 y 35 años; realización de un ultrasonido transvaginal cada seis meses a un año para descartar neoplasia ovárica, así como deter-minación de niveles de CA-125 en suero. El CA- 125 (una glucoproteína de la superficie celular) es un marcador tumoral que se encuentra elevado en la mayoría de los cánceres de ovario asintomáticos; el ultrasonido transabdominal estima correctamente el volumen ovárico, pero no es adecuado para distinguir entre lesiones malignas y benignas; en varonesel examen rectal y la determinación del antígeno prostático seroespecífico deberían ser hechos cuando menos cada año, iniciando a los 50 años. El examen colorrectal debería ser realizado tanto en varones como en mujeres iniciando a la edad de 50 años(Burke \& Daly, 2007)
La mastectomía profiláctica como una opción para la prevención de CM debe ser puesta en considera-ción en este tipo de pacientes. Las indicaciones específicas para una mastectomía profiláctica incluyen una historia familiar y personal de $\mathrm{CM}$, múltiples biopsias previas, resultados no confiables a la explo-ración física debido a mamas nodulares, hallazgos de tejido mamario denso en la mamografía, mastodinia y cancerofobia. Aunque hasta hace poco tiempo no existía evidencia suficiente de que la mastectomía profiláctica eliminara el riesgo de padecer CM en po-sibles portadoras, Lynn y cols haciendo un estudio retrospectivo en mujeres con historia familiar de $\mathrm{CM}$, compararon aquellas posibles portadoras que habían optado por la mastectomía bilateral con las que no habían recibido tal procedimiento. En este es-tudio, la mastectomía profiláctica fue asociada a una reducción en la incidencia de CM del 90\%. La ovariectomía debe también ser puesta en consideración como otra alternativa para disminuir el riesgo de pa-decer cáncer de ovario, aunque el riesgo nunca es de cero, ya que se han descrito algunos casos que poste-riormente desarrollaron cáncer peritoneal.

No existe evidencia suficiente para recomendar el abandono del uso de anticonceptivos orales. El tamoxifeno es recomendado como agente anti estrogénico en mujeres diagnosticadas con cáncer de mama, ya que reduce el riesgo de recurrencia de cáncer contralateral. Han sido realizados estudios para determinar la utilidad del tamoxifeno en la prevención del CM.

El raloxifeno es otro modulador selectivo del receptor de estrógenos que ha sido implicado en la re-ducción del riesgo de desarrollar CM. Cummings y cols., analizando 7,705 mujeres posmenopáusicas de 180 centros clínicos de 25 países, no seleccionadas por riesgo, encontraron cuatro veces menos frecuencia de CM entre el grupo tratado con raloxifeno que en el grupo control. Según este estudio, es necesario tratar a 126 mu- 
jeres para prevenir un caso de cáncer. El raloxifeno disminuye el riesgo de CM receptor de estrógenos positivo en un 90\%, pero no el CM invasivo receptor de estrógenos negativo. El raloxifeno también incrementó el riesgo de eventos tromboembólicos en una proporción de 3 a 1 con respecto al grupo control, pero no la frecuencia de cáncer de endometrio. Actualmente se encuentra en curso el proyecto STAR que tiene como propósito comparar al tamoxifeno y al raloxifeno en su capacidad de pre-vención del CM.

Aunque no existen datos suficientes disponibles acerca del beneficio de modificaciones al estilo de vida, es recomendable el uso de dietas bajas en grasa y altas en fibra, adecuada ingesta de frutas y vegetales, realizar ejercicio regularmente y evitar potenciales carcinógenos como el cigarro.

El manejo de estos pacientes debe ser hecho por un equipo multidisciplinario compuesto de genetis-tas, oncólogos, consejeros genéticos, enfermeras on-cólogas, psicólogos y/o psiquiatras y trabajadores sociales. En estas familias es necesario el asesoramiento genético acerca de riesgos estimados y la vigilancia de los individuos susceptibles. Aspectos como la calidad de vida, y otras consideraciones personales deben ser tomados en cuenta. Debido a que las recomendaciones están basadas en beneficios potenciales, pero aún no probados, las decisiones acerca del tiempo y métodos a utilizar debe ser compartido entre el paciente y el equipo médico que lo supervisa, después de revisar la evidencia disponible.

El aspecto psicológico en pacientes y portadores debe también ser tomado en cuenta, por lo cual el equipo debe incluir psicólogos y/o psiquiatras, ya que la respuesta a un resultado positivo de la prueba es incierta, pudiendo generar ansiedad, depresión o incluso alteraciones más severas. Por otro lado, un resultado negativo podría no ser necesariamente tranquilizador para la paciente, ya que podría generar angustia al no saber cuál o cuáles factores están incrementando el riesgo en su familia. Por lo tanto, es responsabilidad del equipo salvaguardar hasta donde sea posible la integridad del paciente en este aspecto. Es recomendable que el resultado no sea dado a los portadores menores de 18 años directamente, sino a sus padres o tutores. Los resultados deben ser confidenciales protegiendo la privacidad de los pacientes y asegurar que cada miembro de la familia participe y reciba el resultado por su propia voluntad y no influenciado por presiones familiares.

Una razón frecuentemente argüida por las pacientes para rechazar hacerse la prueba de identificación de mutaciones es el temor de que si los resultados son positivos, esto pueda causar discrimina-ción tanto para la obtención de empleos, como para la obtención de seguros o el costo de las primas de los mismos. La razón más frecuentemente manifes-tada por las pacientes para aceptar realizarse la prueba, es conocer el riesgo de desarrollar CM en su familia, principalmente en las hijas.

El manejo de las pacientes de alto riesgo idealmente debe ser realizado en clínicas especializadas en atender casos familiares de cáncer, tal como ocurre en Inglaterra, donde las clínicas de cáncer familiar fueron establecidas en 1946 y actualmente están organizadas de una manera regional. Las clíni-cas familiares proveen especialistas clínicos experimentados en genética, oncología, psicología y consejería. En Francia, la French Cooperative Group Network ha sido formada para coordinar la colección de datos de tales clínicas y ha sido altamente eficiente en identificar familias con ciertos fenotipos de cáncer para estudios colaborativos internacionales. Estas clínicas aseguran un manejo más adecuado de las pacientes y sus familias, debido a que existe la interacción de diversos expertos que se encuentran en una misma área, a los cuales

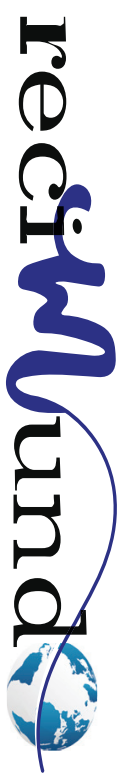


puede ser canalizada la familia. En países donde estas clínicas no existen, los médicos deben contar con guías adecuadas para la evaluación e interpre-tación de la historia familiar; establecer los mecanismos que permitan la interacción entre genetistas y aquellos que proporcionan la ayuda primaria a los pacientes y el establecimiento de un sistema de vigilancia y manejo sistemático de estos pacientes.

Además de los aspectos médico y científico, el arribo al conocimiento de la estructura y tipo de mutaciones en BRCA1 y BRCA2 ha generado también problemas de tipo comercial. Después del descubrimiento del gen BRCA1, compañías estadounidenses se enfrascaron en una pugna por la patente de este gen. Lo mismo ocurrió con el gen BRCA2 después, sólo que esta vez la pugna ocurrió entre una compañía estadounidense y una inglesa.

\section{Conclusiones}

El gen BRCA1 se identificó y clonó en 1994 en función de su vinculación a principiosaparición de cáncer de mama y síndromes de cáncer de mama y ovario en mujeres. Mientraslas mutaciones hereditarias de BRCA1 son responsables de aproximadamente el $40-45 \%$ de las enfermedades hereditarias.cánceres de mama, estas mutaciones representan solo el $2-3 \%$ de todos los cánceres de mama, ya queEl gen BRCA1 rara vez muta en cánceres de mama esporádicos. Sin embargo, BRCA1la expresión es frecuentemente reducida o ausente en cánceres esporádicos, lo que sugiere una gran cantidadpapel más amplio en la carcinogénesis mamaria. Desde que BRCA1 fue clonado en 1994, suLa función molecular ha sido objeto de una intensa investigación. Estos estudios tienenreveló múltiples funciones de BRCA1 que pueden contribuir a su tumoractividad supresora, incluyendo roles en: progresión del ciclo celular, varios altamenteprocesos especializados de reparación de $A D N$, puntos de control del ciclo celular que responden al daño del ADN,regulación de un conjunto de vías transcripcionales específicas y apoptosis. Muchosde estas funciones están vinculadas a proteínas: interacciones de proteínas que involucran diferentesporciones de la proteína BRCA1 de 1,863 aminoácidos (aa). BRCA1 funciona en el ciclo celularLa progresión y la respuesta al daño del ADN parecen estar reguladas por distintas yeventos específicos de fosforilación, pero las vías moleculares activadas por estosLas fosforilaciones apenas comienzan a desmoronarse. Además, la razón por la quelos portadores de la mutación BRCA1 desarrollan tipos de tumor específicos (cánceres de mama y de ovario)en mujeres y posiblemente cánceres de próstata en hombres) no se entiende claramente.La aclaración de las funciones moleculares precisas del producto genético BRCA1mejoran en gran medida nuestra comprensión de la patogénesis hereditaria, así comocarcinogénesis mamaria esporádica.

\section{Bibliografía}

Bolívar, J. (2015). Investigación Documental. México. Pax.

Bondy, M., \& Spitz, M. (2012). Low inciden-ce of familial breast cancer among Hispanic women. . Cancer Causes and Control, 377-82.

Boyd, M., \& Harris, F. (2015). A human BRCA1 gene knockout. Nature, 541-42.

Burke, W., \& Daly, M. (2007). Consensus statement. Recommendations for follow-up care of individuals with an inherited predisposition to cancer. BRCA1 and BRCA2. . JAMA, 997-1003.

Castro, J. (2016). Técnicas Documentales. México. Limusa.

Chu, K., \& Tarone, R. (2016). Recent trends in U.S. breast cancer incidence, survival, and mortality rates. J Natl Cancer Inst, 1571-9.

Davila, A. (2015). Concepto de terminos cientificos. Caracas: Oasis.

Easton, D., Bishop, D., \& Ford, D. (2012). Crockford GP and The Breast Can-cer Linkage Consortium. Genetic linkage analysis in familial breast and ovarian cancer. Results from 214 families. Am J Hum Genet, 678-701. 
Goss, P., \& Sierra, S. (2011). Current perspectives on radiation-induced breast cancer. . J Clin Oncology, 338-46.

Henderson, C., \& Patek, A. (2007). Are breast cancers in young women quali-tatively distinct? Lancet, 1448-49.

Hill, A., \& Doyle, J. (2007). Hereditary Breast Cancer. B J Surg, 1334-39.

Holford, T., Roush, G., \& McKay, L. (2011). Trends in female breast cancer in Connecticut and the United States. . J Clin Epidemiol , 29-39.

Holt, J., \& Thompson, M. (2006). Growth retardation and tumour inhibition by BRCA1. . Nat Genet, 298302 .

Hoskins, K., Stopfer, \& JE. (2005). Assessment and counseling for women with a family history of breast cancer. A guide for clinicians. . JAMA, 577-85

Jensen, R., \& Thompson, M. (2006). BRCA1 is secreted and exhibits properties of a grani-na. Nat Genet, 303-08.
Narod, S., \& Feuteun, J. (2011). Familial breast-ovarian cancer locus on chromosome 17q21-21. Lancet, 82-83.

Pisani, P., Parkin, D., \& Bray, F. (2009). Estimates of the worldwide mortality from cancers. Int J Cancer, 18-29.

Seitz, S., Rohde, K., \& Bender, E. (2017). Strong indication for a breast cancer susceptibility gene on chro-mosome 8p12-p22: Linkage analysis in German breast cancer fami-lies. Oncogene , 741-43.

Shattuck-Eidens, D., McClure, M., Simard, J., Labrie, F., \& Narod, S. (2005). A collaborative survey of 80 mutations in the BRCA1 breast and ovarian cancer susceptibility gene. JAMA, 535-4.

Tokunaga, M., \& Land, C. (2009). Incidence of female breast cancer among atomic bomb survivors,. Radiat Res, 209-23.

Trichopoulos, D, \& Macmahom, B. (2002). Menopause and breast can-cer risk. . JNCl, 48: 605.

Ursin, G., \& Henderson, B. (2017). Does oral contraceptive use increase the risk of breast cancer in women with BRCA1/BRCA2 mutations more than in other wo-men? . Cancer Research, 3678-81.

\section{CITAR ESTE ARTICULO:}

Almeida Barba, K., Castillo González, A., Fuertes Arévalo, R., \& Rodríguez Becerra, D. (2020). Cáncer de mama ligado al gen BRCA1. RECIMUNDO, 4(1(Esp)), 100-113. doi:10.26820/recimundo/4.(1).esp.marzo.2020.100-113 